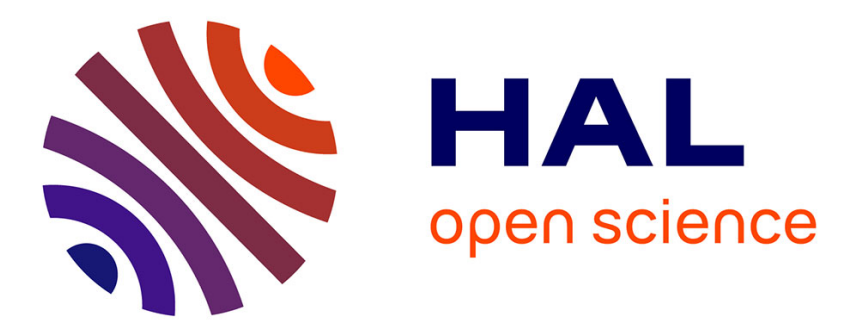

\title{
Ex Vivo Complement Activation on Endothelial Cells: Research and Translational Value
}

Marie-Sophie Meuleman, Veronique Fremeaux-Bacchi, Lubka T Roumenina, Sophie Chauvet

\section{To cite this version:}

Marie-Sophie Meuleman, Veronique Fremeaux-Bacchi, Lubka T Roumenina, Sophie Chauvet. Ex Vivo Complement Activation on Endothelial Cells: Research and Translational Value. Trends in Molecular Medicine, 2021, 27 (5), pp.418-421. 10.1016/j.molmed.2021.01.008 . hal-03262373

\section{HAL Id: hal-03262373 https://hal.science/hal-03262373}

Submitted on 16 Jun 2021

HAL is a multi-disciplinary open access archive for the deposit and dissemination of scientific research documents, whether they are published or not. The documents may come from teaching and research institutions in France or abroad, or from public or private research centers.
L'archive ouverte pluridisciplinaire $\mathbf{H A L}$, est destinée au dépôt et à la diffusion de documents scientifiques de niveau recherche, publiés ou non, émanant des établissements d'enseignement et de recherche français ou étrangers, des laboratoires publics ou privés. 


\section{Ex-vivo complement activation on endothelial cells: research and translational value}

Marie-Sophie Meuleman, Veronique Fremeaux-Bacchi, Lubka T Roumenina*, Sophie Chauvet*

Centre de Recherche des Cordeliers, INSERM, Sorbonne Université, Université de Paris, F75006 Paris, France.

*Correspondence:

Sophie Chauvet

Department of nephrology, European Hospital Georges Pompidou, APHP, Paris, FR INSERM 1138, Cordelier research center, Paris, FR e-mail: Sophie.chauvet@aphp.fr

Or

Lubka T. Roumenina

Cordeliers Research Center, INSERM UMRS 1138;

15 rue de l'Ecole de Medecine; 75006 Paris, France

e-mail: lubka.roumenina@sorbonne-universite.fr

\section{Keywords}

Complement; Endothelial Cells; Diagnostics; Kidney injury

\section{Abstract}

The spectrum of human diseases with complement contribution is ever increasing. Tools to study the complement contribution and the potential interest of novel complement inhibitors in clinical practice are lacking. Here we discuss a functional ex-vivo assay to monitor complement activation on endothelial cells, which can answer to this need. 


\section{Complement in diseases and currently available tests for its exploration.}

Complement is important part of innate immunity (Box 1), but can also, when overactivated, cause tissue damage. While complement overactivation is the central mechanism of cell and tissue injury in complement mediated diseases as atypical Hemolytic and Uremic Syndrome (aHUS), C3 Glomerulopathy and Paroxysmal Nocturnal Hemoglobinuria, contribution of complement has been reported in pathophysiological processes of a large variety of conditions (i.e Age-related Macular Disease, Antibody Mediated rejection, Cryoglobulinemic Vasculitis, IgA vasculitis, Systemic Lupus Erythematous, Anti-Phospholipid Syndrome, ANCAassociated vasculitis, Rheumatoid Arthritis, HELLP syndrome, pre-eclampsia, Sickle Cell Disease $(S C D)$ ) in which vascular endothelium is one of the first targets of the overactive complement. Complement-blocking therapeutics are now considered in these diseases. Therefore, there is an unmet need of tools, allowing disease-relevant evaluation of which patient could benefit from such therapeutic approach.

Exploration and demonstration of complement overactivation and its implication in human disease is a cornerstone of the diagnosis and management. Most of the tests, currently available, consist of 1 ) the quantification of complement activation fragments released in blood or 2) deposited on tissue or relay on 3) lysis of animal erythrocytes or 4) C5b-9 deposition in an ELISA plate. More specific functional tests, including hemolytic assays, exploring specific steps of the AP regulation ( $\mathrm{FH}$ functional defect or $\mathrm{C} 3$ convertase stabilization) still lack approved international standards, are used by small number of specialized laboratories[2]. Only few assays, such as the $\mathrm{CH} 50$ hemolytic test, are used to follow complement-targeting treatment but this test is not well correlated with disease activity and relapses risk[3]. Despite the increased understanding of the contribution of complement in diseases, validated assays, judging whether complement inhibition will be 
therapeutically relevant are missing. Therefore, there is a real need to develop tools to demonstrate the implication of complement in diseases in order to adjust treatment regiments and improve patient's management.

\section{Endothelial cells assay: could it be used to improve patient management?}

In order to explore the complex interplay between complement and human cells, several authors proposed to quantify complement fragments deposition on endothelial cells (EC) incubated with serum or plasma from patients with different pathological conditions (Figure 1). This ex vivo assay is the closest to the physiological context available and holds great promise. Nevertheless, there are several unanswered questions and obstacles to overcome.

-Which EC to be used? Main EC type used for this assay are HMEC-1[3-6], immortalized Human dermal Microvascular Endothelial Cells (HMEC); HUVEC[7-10], primary macrovascular EC from human umbilical vein, Cl-GEnC[7-9], conditionally immortalized glomerular EC; phosphatidylinositol-specific phospholipase C-treated EA.hy926 cells EC line and PIGA-mutant TF-1 (non-endothelial)[11]. Obtained results with these cells are generally similar. Nevertheless, these cells differ in their expression of complement regulators and susceptibility to stress stimuli, such as heme[12] with higher C3 deposit, weaker FH binding and Thrombomodulin up-regulation in CI-GEnC compared to HMEC and HUVEC. Optimally, the assay should be performed with a cell line that is well characterized, widely available and easy to use, as HMEC-1, to avoid the inter-cellular variability, which may be expected with primary cells. 
-Is EC pre-activation needed? Resting or pre-activated (by cytokines, ADP or heme) EC can be used, providing complementary information. The use of resting EC seems to generate more specific results, with a correlation of increase deposits on quiescent HEMC-1 with relapse risk during Eculizumab dosage tapering or discontinuation[3]. On the opposite, pre-activated EC provide more sensitive results with positivity while incubated with serum from asymptomatic carriers of mutations in AP regulatory proteins or C3 $[4,7]$.

-Serum or activated plasma? While most of the studies used patients' serum as complement source[3,4,6-10], Palomo et al proposed to use patient citrated plasma mixed with control serum pool (1:1). This allows a lower coefficient of variation of data, namely 9 to $18 \%[5]$ as compared to 30 to $52 \%$, with patient sera. The rational for the citrate use might be an interaction between coagulation and complement cascade, as illustrated by collocated fibrin and C5b-9 deposits. Patient-derived autoantibodies could be tested when added to normal human sera (NHS), as for anti-C3b in lupus nephritis[13]or recombinant patient mutationscarrying proteins, when added in depleted serum, as done for Factor B in aHUS[8].

-Which controls are needed? An international standard and validated positive and negative controls are needed for this test. The most frequently used negative control is a set of NHS[3,4,7-10] or pooled NHS, to avoid the inter-individual variability in deposits induced by normal sera[3,5,6]. Often positive control is lacking[3-5,8] while its use could allow standardization, comparability and, after titration, an establishment of a standard curve for quantification. Positive controls can be FH- or Fl-depleted NHS[7] but due to their poor reproducibility, a better choice could be a NHS spiked with blocking anti-FH antibodies against the $\mathrm{N}$-terminus or $\mathrm{C}$-terminus[9]. 
-Which deposits are relevant to measure? Quantification of complement activation products deposits on EC surface reflects the complement over-activation or deregulation when EC are incubated with samples of interest. While C3b/iC3b deposits reflect the early steps, $C 5 b-9$ is the final product of the cascade. Thus $C 5 b-9$ deposits might be more relevant to identify a deregulation at any step. Nevertheless, an early deregulation could induce C3 activation fragments deposits without C5b-9 formation because of a TP regulation. Since they provide complementary information, both C3b and C5b-9 deposit should be measured.

- Which activation pathway? In order to assess which complement pathway is activated, the test can be performed in presence of Mg-EGTA in the serum[9] to block CP and LP, leaving only the AP active, while EDTA blocks all three pathways. The assay can evaluate only abnormalities present in the circulation. If there is a genetic abnormality in the membrane expression of MCP in the patient for example, it cannot be detected by this test.

- How to detect and quantify deposits? Flow cytometry (FACS)[7-10] and immunofluorescence (IF) $[3-5,9,10]$ can be used for quantification. Similar results were obtained when HUVEC pre-activated with heme were incubated with NHS or aHUS patients sera[9] or SCD patients sera[10]. While IF allows a direct analysis of the deposits on EC adherent on slide, FACS requires a cell detachment that may lead to a partial loss of signal. FACS provides rapid and objective quantification. On the opposite, quantification step by IF requires a supplementary standardization to allow comparability and reproducibility. Deposits quantification by IF usually implies measurement of the area occupied by fluorescent staining in fields systematically captured on the slide and is expressed as mean 
of pixel $^{2}$ per field, then compared with negative control[3-6]. Quantification of the number/density of EC on which deposits are detected or the ratio surface of the deposits area/number of nuclei might be relevant and helpful to standardize this step.

- Why complement is activated? Initially, positivity was reported in aHUS patients and their healthy relatives, carrying complement mutations[4,7] or in aHUS model conditions (reconstitution of FB-depleted serum with recombinant WT or mutant FB[8]). Nevertheless, aHUS patients without genetic/acquired complement abnormality, some mutation-negative healthy relatives or patients with diseases lacking complement mutations/autoantibodies were reported positive[5,6,10,14]. Therefore, the mechanism behind complement deposition is more complex. These individuals may have a circulating defect, resulting in complement dysregulation on the endothelium. For SCD samples, cell-free heme seems responsible for the complement activation as it can be prevented by heme scavenging with hemopexin[10]. The use of hemopexin or other inhibitors yet to be defined could help to distinguish the mechanism by which complement is activated, i.e. due to complement abnormality or due to activator present in the circulation. Some drugs could also act as a trigger of complement activation, as Carfilzomib which induces Thrombotic MicroAngiopathy (TMA)[15]. Therefore, this test is not specific for complement genetic/acquired abnormalities, but turns positive in a large spectrum of diseases, where complement and/or EC activating factors are present in the circulation.

-For which indications? This assay was developed for aHUS[7-9], but additional studies suggest its utility to explore complement contribution to pathophysiology of other diseases, such as HELLP syndrome and pre-eclampsia[5], TMA associated with severe hypertension[6], 
SCD[10], Carfilzomib induced TMA[15] to name a few. Finally, Galbusera et al and Palomo et al proposed the EC assay as a tool for Eculizumab therapy management in patients with aHUS[3,5].

\section{Concluding Remarks}

Ex vivo complement activation assay could represent a useful tool to demonstrate complement involvement in a given disease. With the current development of complement blockers and in the field of precision medicine, it may allow to better personalize and monitor such therapeutics. Nevertheless, it first has to be well standardized in bona fide complement mediated diseases, to allow comparability and reproducibility.

\section{Box 1: Brief overview of complement system.}

As part of innate immunity, complement plays a key role in host homeostasis, inflammation and in the defense against pathogens[16]. It is composed by more than 30 soluble and membrane bound proteins, which coordinated action represents a first line of defense. It can be activated through three different pathways: the classical pathway (CP), lectin pathway (LP) or the alternative pathway (AP). When activated these serine protease cascades converge to a terminal pathway (TP), generating cleavage products as anaphylatoxins ( $\mathrm{C} 3 \mathrm{a}$ and $\mathrm{C} 5 \mathrm{a})$, opsonin $(\mathrm{C} 3 \mathrm{~b} / \mathrm{iC} 3 \mathrm{~b})$ and the membrane attack complex (MAC). CP and LP activation follows the recognition of Pathogen-Associated Molecular Patterns (PAMPS) or Danger-Associated Molecular Patterns (DAMPS) by Pattern Recognizing Molecules (PRM). Their activation is Ca-dependent and results in the formation of classical C3 convertase: C4b2a. Conversely, AP is constantly activated at low level in fluid phase and generates small quantity of C3b. C3b can bind activator surface (apopto-necrotic or 
bacterial) and thus initiate $\mathrm{Mg}$-dependent alternative $\mathrm{C} 3$ convertase formation ( $\mathrm{C} 3 \mathrm{bBb})$. Covalent bound $\mathrm{C} 3 \mathrm{~b}$ associates with $\mathrm{FB}$ to form AP C3 proconvertase (C3bB) and then, by FD activation, forms AP solid phase $\mathrm{C} 3$ convertase $(\mathrm{C} 3 \mathrm{bBb}) . \mathrm{C} 3 \mathrm{bBb}$ is a powerful enzyme that catalyzes further cleavage of $\mathrm{C} 3$ : it is the amplification loop. To avoid self-aggression, AP is highly regulated on host cells, notably endothelial cells (EC). Main regulator, FH can compete with $\mathrm{FB}$ for $\mathrm{C} 3 \mathrm{~b}$ binding, is $\mathrm{FI}$ cofactor for $\mathrm{C} 3 \mathrm{~b}$ inactivation in $\mathrm{iC} 3 \mathrm{~b}$ and can induce $\mathrm{C} 3 \mathrm{bBb}$ dissociation. MCP (CD46) and CR1 are others, membrane bound, FI cofactors for the inactivation of $\mathrm{C} 3 \mathrm{~b}$ to $\mathrm{iC} 3 \mathrm{~b}$. DAF (CD55) is another membrane bound regulator implicated in AP C3 convertase dissociation. Lastly, CD59 inhibits final C9 polymerization and MAC formation. A defect in these regulators can lead to inadequate complement activation at EC surface and become a disease cause as in atypical Hemolytic and Uremic Syndrome (through anti-FH antibody, FH, FI or MCP mutations).

\section{Acknowledgements}

This work is supported by an ANR JCJC to S.C.

The authors declare no conflict of interest.

\section{References}

1 Dijkstra, D.J. et al. (2019) Complement activation and regulation in rheumatic disease. Semin. Immunol. 45, 101339

2 (2020) COMPLEMENT SYSTEM: innovative diagnostic and research protocols., HUMANA.

3 Galbusera, M. et al. (2019) An Ex Vivo Test of Complement Activation on Endothelium for Individualized Eculizumab Therapy in Hemolytic Uremic Syndrome. Am. J. Kidney Dis. 74, $56-72$

4 Noris, M. et al. (2014) Dynamics of complement activation in aHUS and how to monitor eculizumab therapy. Blood 124, 1715-1726

5 Palomo, M. et al. (2019) Complement Activation and Thrombotic Microangiopathies.

Clin. J. Am. Soc. Nephrol. 14, 1719-1732 
6 Timmermans, S.A.M.E.G. et al. (2018) C5b9 Formation on Endothelial Cells Reflects Complement Defects among Patients with Renal Thrombotic Microangiopathy and Severe Hypertension. J. Am. Soc. Nephrol. 29, 2234-2243

7 Roumenina, L.T. et al. (2012) A prevalent C3 mutation in aHUS patients causes a direct C3 convertase gain of function. Blood 119, 4182-4191

8 Roumenina, L.T. et al. (2009) Hyperfunctional C3 convertase leads to complement deposition on endothelial cells and contributes to atypical hemolytic uremic syndrome. Blood 114, 2837-2845

9 Frimat, M. et al. (2013) Complement activation by heme as a secondary hit for atypical hemolytic uremic syndrome. Blood 122, 282-292

10 Roumenina, L.T. et al. (2020) Complement activation in sickle cell disease:

Dependence on cell density, hemolysis and modulation by hydroxyurea therapy. Am. J. Hematol. 95, 456-464

11 Gavriilaki, E. et al. (2015) Modified Ham test for atypical hemolytic uremic syndrome. Blood 125, 3637-3646

12 May, O. et al. (2018) Heme Drives Susceptibility of Glomerular Endothelium to Complement Overactivation Due to Inefficient Upregulation of Heme Oxygenase-1. Front. Immunol. 9,

13 Vasilev, V.V. et al. (2015) Functional Characterization of Autoantibodies against Complement Component C3 in Patients with Lupus Nephritis. J. Biol. Chem. 290, 2534325355

14 Piras, R. et al. (2020) Molecular Studies and an ex vivo Complement Assay on Endothelium Highlight the Genetic Complexity of Atypical Hemolytic Uremic Syndrome: The Case of a Pedigree With a Null CD46 Variant. Front. Med. 7, 579418

15 Blasco, M. et al. (2020) Complement as the enabler of carfilzomib-induced thrombotic microangiopathy. Br. J. Haematol. DOI: 10.1111/bjh.16796

16 Merle, N.S. et al. (2015) Complement System Part II: Role in Immunity. Front. Immunol. 6,

\section{Figure legend}

Figure 1: Endothelial cells assay: could it be used to improve patient management? 
Complement deregulation contributes to a large variety of conditions, in particular in atypical Hemolytic and Uremic Syndrom (aSHU) in which it is central mechanism of endothelial cell injury

Development of such assay could help to better characterise tissu and organ injury and justify and monitor complement blocking therapy

In order to develop a more

pathophysiologic based medecine
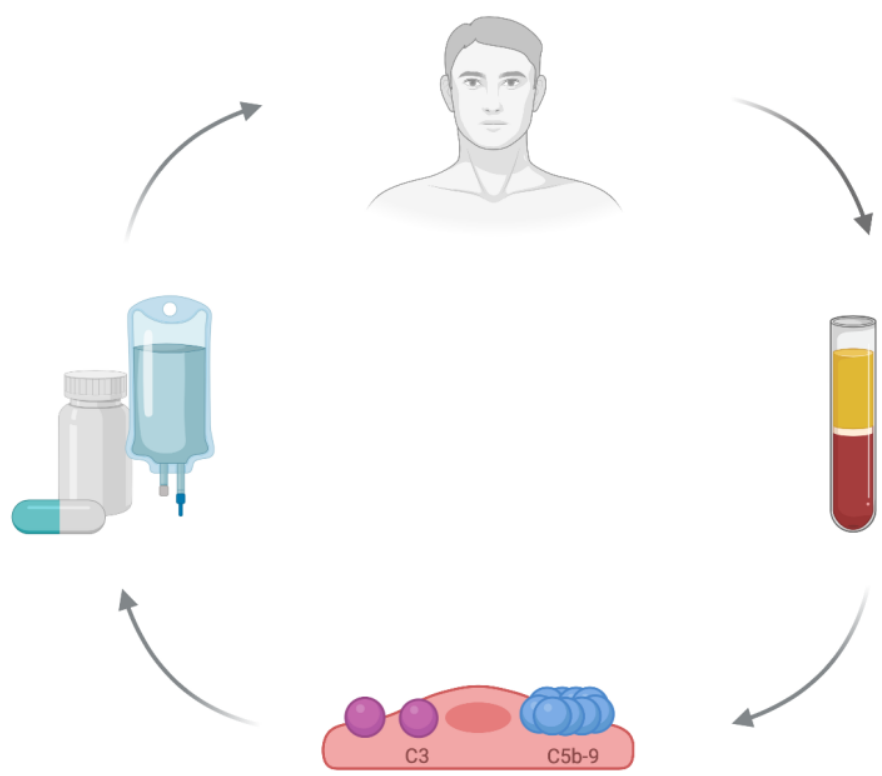

Ex vivo quantification of complement fragments deposition on endothelial cells incubated with patient serum or plasma could answer to this need but first have obstacles to overcome
Exploration and demonstration of complement overactivation in blood samples is cornerstone, but current available tests lack international standard and have limited appliccability in clinical practice 